\title{
Elimination by Ethidium Bromide of Antibiotic Resistance in Enterobacteria and Staphylococci
}

\author{
By D. H. BOUANCHAUD, M. R. SCAVIZZI AND Y. A. CHABBERT \\ Pasteur Institute, Paris (XV), France
}

(Accepted for publication 6 August 1968)

\section{SUMMARY}

Ethidium bromide, a trypanocidal drug affecting nucleic acid synthesis, was found to be a powerful agent in eliminating some antibiotic resistance in bacteria. In staphylococci, penicillinase production was eliminated in mercury-resistant organisms, but not in mercury-sensitive ones. Among enterobacteria, two resistance factors showing the same resistance pattern were differently eliminated, and correlation between elimination and transfer of resistance factors was not always observed. $\mathrm{F}^{\prime}$-lac ${ }^{+}$factor was also eliminated by ethidium bromide in Escherichia coli KI2. Elimination of antibiotic resistance was observed generally at high frequency, and could be better reproduced than with acridine dyes.

\section{INTRODUCTION}

Many genetic determinants of antibiotic resistance in Enterobacteriaceae and Staphylococcus have been shown to belong to extrachromosomal elements; genetic studies on this subject have been reviewed by Mitsuhashi $(1965,1967)$, Watanabe (1967) and Novick (1967). These drug-resistance determinants are transmissible to sensitive bacteria independently of chromosomal genes and like the sex factor they can be eliminated by acridine dyes, but generally at low frequencies. Recently, Ikeda, Iijima \& Tajima (1967) reported that the sex factor in a male strain of Escherichia coli KI2 was eliminated by sarkomycin, which was however less active than acridine orange. Elimination of antibiotic resistance at high frequency is of interest to assert extrachromosomal location of genetic determinants, and drugs with better eliminating or 'curing' effect are needed. Previous investigations have shown that ethidium bromide binds to DNA and RNA, and inhibits DNA-polymerase and RNA-polymerase (Waring, 1966). Like the acridines, ethidium bromide was intercalated between base-pairs of DNA. The complex between ethidium bromide and nucleic acids has been described by Lepecq \& Paoletti (1967), and biochemical effects of this drug on bacteria were reported by Tomchick \& Mandel (1964). The present paper summarizes the effects of ethidium bromide on antibiotic resistance in some multiresistant enterobacteria and staphylococci.

\section{METHODS}

Bacteria and culture media. Resistant enterobacteria (obtained from International Centre for Salmonella, Pasteur Institute, and Pasteur Hospital laboratory) were as described by Chabbert \& Baudens (1966) and Baudens \& Chabbert (1967). Escherichia coli $\mathrm{KI} 254 \mathrm{I} 17 \mathrm{~F}^{-} \mathrm{lac}^{+}$and $E$. coli $\mathrm{KI} 2 \mathrm{C}^{2} 00 \mathrm{~F}^{-} \mathrm{lac}^{-}$were provided by Dr E. L. Wollman, and $E$. coli $\mathrm{KI} 2 \times 200 \mathrm{PS}$ lac ${ }^{-}$carrying $\mathrm{F}^{\prime}$-lac ${ }^{+}$factor by Dr F. Jacob (Pasteur Institute, 
Paris). The conjugation conditions used were as described by Watanabe \& Fukasawa (196I). Nine strains were used for the present work: Samonella oranienburg LA39.R4 (resistant to $\mathrm{Sm} \mathrm{Km} \mathrm{Cm} \mathrm{Tc} \mathrm{Su}$ ); S. paratyphi B LA43.R8 ( $\mathrm{Sm} \mathrm{Cm} \mathrm{Su}$ ); S. panama LA46.RII (Am Km Tc); S. paratyphi B LA47.RI3 (Am Sm Cm Tc Su); E. coli ( I I :B4) LA49.RI5 (Am Sm Cm Tc Su); Shigella flexneri LA56.R22 (Am Sm Cm Tc $\mathrm{Su}$ ); S. stanleyville LA 68.R32 (Am Sm Km Cm Tc Su); S. oranienburg LA69. R33 (Am Sm); S. derby LA7I.R35 (Am Sm Su); E. coli KI2 54II7.R22; C600.R22; 54II7.RI5; C600.RI5 were obtained by transfer of factors R22 and RI5 from Sh. flexneri LA56.R22 and $E$. coli LA49.RI 5 to sensitive strains of $E$. coli KI2.

Eight strains of Staphylococcus aureus (coagulase-positive) isolated from clinical material were used. Drug-resistance patterns were: LA72: P Hg Sm Tc Em; LA75: P Sm Km Tc Em; LA78: P Hg Tc Em; LA80: P; LA82: P Hg Sm Tc Em; LA86: P Hg Em; LA87: P Sm Tc Em; LA89: P Hg Sm Km Tc Em. Penicillin resistance determinant was transduced from LA75 to $S$. aureus 209P (ATCC: 65.38P) by phage 53 (NCTC 8406), as previously described (Chabbert, Baudens \& Gerbaud, 1964). Code key: Am, ampicillin; Sm, streptomycin; Km, Kanamycin; $\mathrm{Cm}$, chloramphenicol; Tc, tetracycline; Su, sulphonamide; $\mathrm{P}$, benzylpenicillin; Em, erythromycin; $\mathrm{Hg}$, $\mathrm{HgCl}_{2}$.

Tryptic soy broth (0370 Difco) and tryptic soy agar (0369 Difco) were routinely used, and the effects of different $\mathrm{pH}$ values were separately studied.

Chemicals. Ethidium bromide (3,8-diamino-5-ethyl-6-phenyl-phenanthridinium) was a gift from Boots Pure Drug Co., Ltd., Nottingham, Great Britain. Benzylpenicillin, dihydrostreptomycin sulphate and sulphamethoxypyridazine were obtained from 'Specia' Rhône-Poulenc, Paris; ampicillin from Delagrange Laboratories, Paris; chloramphenicol and erythromycin from Roussel Laboratories, Paris; tetracycline hydrochloride from Pfizer-Clin Laboratories, Paris.

Determination of ethidium bromide activity on bacterial growth. Minimal inhibitory concentrations of ethidium bromide were determined by the spot-technique on serial dilutions of drug in nutrient agar, and expressed in molarity. Growth curves in nutrient broth were read at $620 \mathrm{~m} \mu$ where light adsorption by ethidium bromide was minimal (Tomchick \& Mandel, 1964).

Determination of antibiotic resistance. Bacteria $\left(\mathrm{I}^{4}\right)$ were inoculated by the spottechnique, using a modification of Steers's apparatus (1959), on nutrient agar supplemented with the following concentrations of antibiotics: benzylpenicillin, $0 \cdot \mathrm{I}$ i.u. $/ \mathrm{ml}$.; ampicillin, $20 \mu \mathrm{g} . / \mathrm{ml}$.; streptomycin, $32 \mu \mathrm{g} . / \mathrm{ml}$.; chloramphenicol, $20 \mu \mathrm{g} . / \mathrm{ml}$.; tetracycline, I6 $6 \mathrm{~g} . / \mathrm{ml}$; ; erythromycin, Io $\mu \mathrm{g} . / \mathrm{ml}$. kanamycin, $12.5 \mu \mathrm{g} . / \mathrm{ml}$.: sulphamethoxypyridazine, $100 \mu \mathrm{g} . / \mathrm{ml}$.

Resistance to mercuric ion was determined with the sensitivity discs described by Novick (1967).

Elimination of antibiotic resistance. A small inoculum ( $\mathrm{I}^{4}$ bacteria $/ \mathrm{ml}$.) was grown overnight at $37^{\circ}$ in nutrient broth containing a subinhibitory concentration of ethidum bromide, giving incomplete inhibition (from 6 to $10 \times 10^{-6} \mathrm{M}$ for staphylococci, and from 60 to $2500 \times 10^{-6} \mathrm{M}$ for enterobacteria). The culture was plated on agar, and isolated colonies tested for antibiotic resistance. In other cases, $\mathrm{IO}^{5}$ bacteria were plated on nutrient agar containing serial dilutions of ethidium bromide and incubated overnight. The plates were flooded with $2 \mathrm{ml}$. broth. Bacterial suspension were homogenized, and bacteria were re-isolated on agar and tested for drug resistance. 
Effect of ethidium bromide on induced synthesis of penicillinase in staphylococci. Exponentially growing staphylococci (strain LA78) were induced for penicillinase synthesis with $\mathrm{I} \cdot 5 \times 10^{-6} \mathrm{M}$-methicillin (Novick \& Richmond, 1965) and ethidium bromide was added $30 \mathrm{sec}$. later to give final concentrations $0,5,10,20,50$ and $100 \times 10^{-6} \mathrm{M}$. Synthesis of penicillinase was stopped at $30 \mathrm{~min}$. by adding chloramphenicol $(50 \mu \mathrm{g} . / \mathrm{ml}$.) to all samples. Bacteria were centrifuged down $(20,000 \mathrm{~g}$ for $5 \mathrm{~min}$. at $4^{\circ}$ ), washed and suspended in phosphate buffer $\left(0^{\circ} \mathrm{I} \mathrm{M}, \mathrm{pH} 5^{\circ}\right)$. The extinctions of bacterial suspensions were adjusted at $620 \mathrm{~m} \mu$, and various dilutions were assayed iodometrically for penicillinase activity (Perret, 1954).

\section{RESULTS}

Elimination of antibiotic resistance in enterobacteria. Typical results are shown in Table I, and others will be reported separately. All drug-resistance determinants in Salmonella oranienburg LA39.R4, Shigella flexneri LA56.R22, Escherichi coli KI2 54I 17. R22 and E. coli KI 2 C600.R22 were eliminated at a high frequency. Spontaneous loss of complete drug resistance was low, and no loss of isolated resistance characters was observed. No significant differences in the elimination of resistance factor $\mathbf{R} 22$ were observed in the originally resistant Sh. flexneri LA56.R22, and E. coli KI2 54I I 7.R22 and C600.R22. In S. derby LA7I . R35 (resistant to ampicillin, streptomycin, sulphonamide) ampicillin resistance was suppressed in $100 \%$ of the organisms by ethidium bromide treatment, but streptomycin and sulphonamide resistances were not modified. The determinant for ampicillin resistance was easily transferred to $E$. coli $\mathrm{KI} 2$ 54I I 7, but determinants for streptomycin and sulphonamide resistance were not transferred.

Kanamycin resistance was significantly eliminated in Salmonella panama LA46. RI I, change in tetracycline resistance was not significant, and loss of ampicillin resistance was not observed. It has been reported that kanamycin resistance was significantly eliminated by acriflavine in this strain (Baudens \& Chabbert, 1967). Nevertheless, all resistance characters were transferred jointly or separately to sensitive bacteria.

With Salmonella stanleyville LA68.R32, S. paratyphi B LA47.RI3, and S. oranienburg LA69.R33, spontaneous loss of single resistance characters was observed, but the frequency was not significantly increased by ethidium bromide treatment. In $S$. paratyphi $B$ LA43.R8 and Escherichia coli LA49.RI5, no elimination of antibiotic resistance was observed.

Elimination of $F^{\prime}$-lac ${ }^{+}$factor by ethidium bromide. Escherichia coli $\mathrm{KI} 2 \times 200$ PS lac ${ }^{-}$carrying $\mathrm{F}^{\prime}-\mathrm{lac}^{+}$factor was treated by ethidium bromide, and organisms were isolated on Drigalski medium. Ethidium bromide, like acridine dyes (Hirota \& Iijima, 1957), eliminated $\mathrm{F}^{\prime}$-lac ${ }^{+}$factor: $20 \%$ of tested colonies were unable to ferment lactose. No spontaneous loss of this factor was observed in controls (I04 colonies).

Elimination of antibiotic resistance in staphylococci. Frequencies of loss of resistance in nine strains of staphylococci are shown in Table 2. Penicillin resistance was eliminated at high frequency ( 8 to $100 \%$ ) in five multiresistant strains. These five strains were resistant to mercuric chloride, and mercury resistance was co-eliminated in all penicillinsensitive colonies. Induced synthesis of penicillinase in Staphylococcus aureus LA78 was partially inhibited at $50 \times \mathrm{IO}^{-6} \mathrm{M}$ and completely inhibited at $100 \times 10^{-6} \mathrm{M}$ ethidium bromide. With four strains, no elimination of penicillin resistance was ob- 


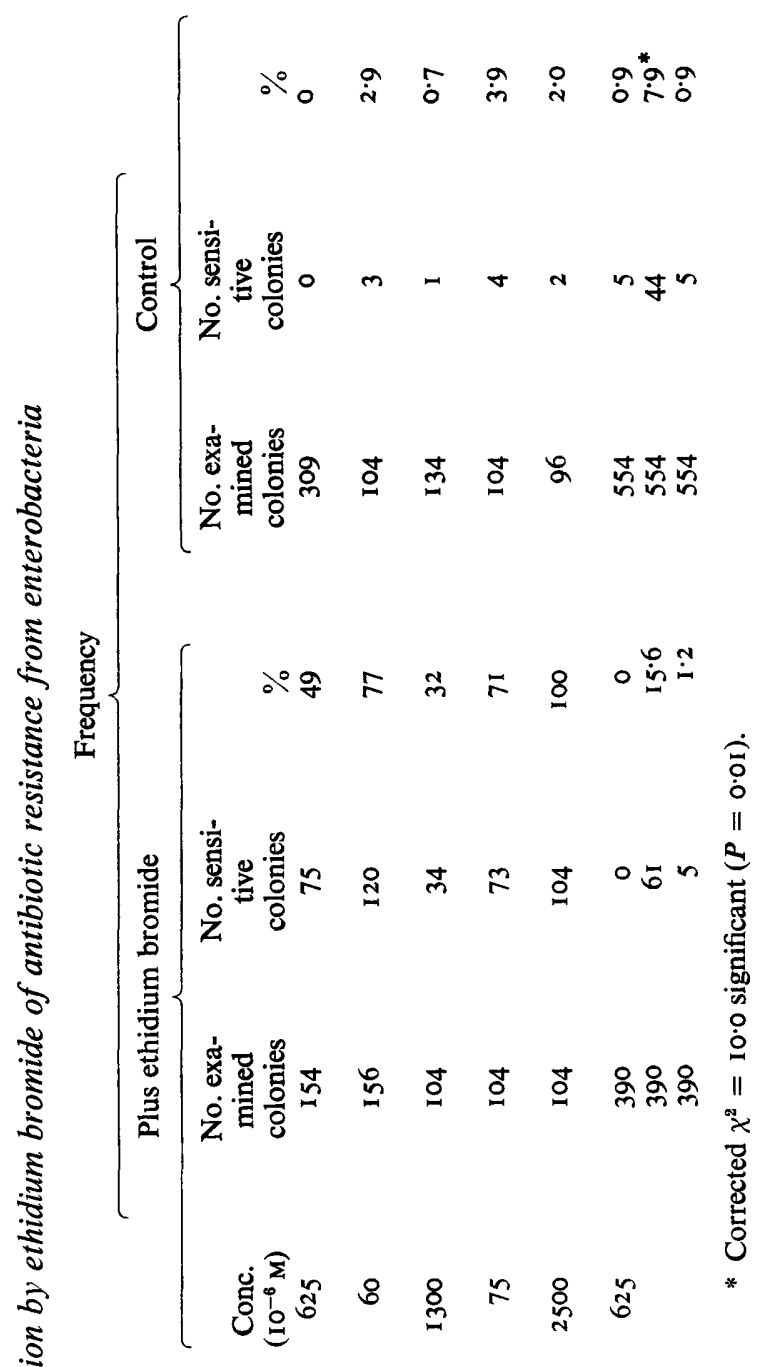

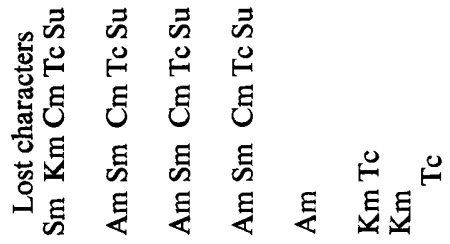

范

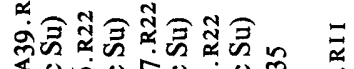

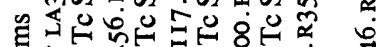

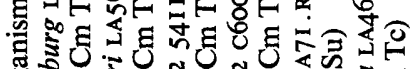

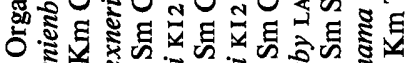
すั

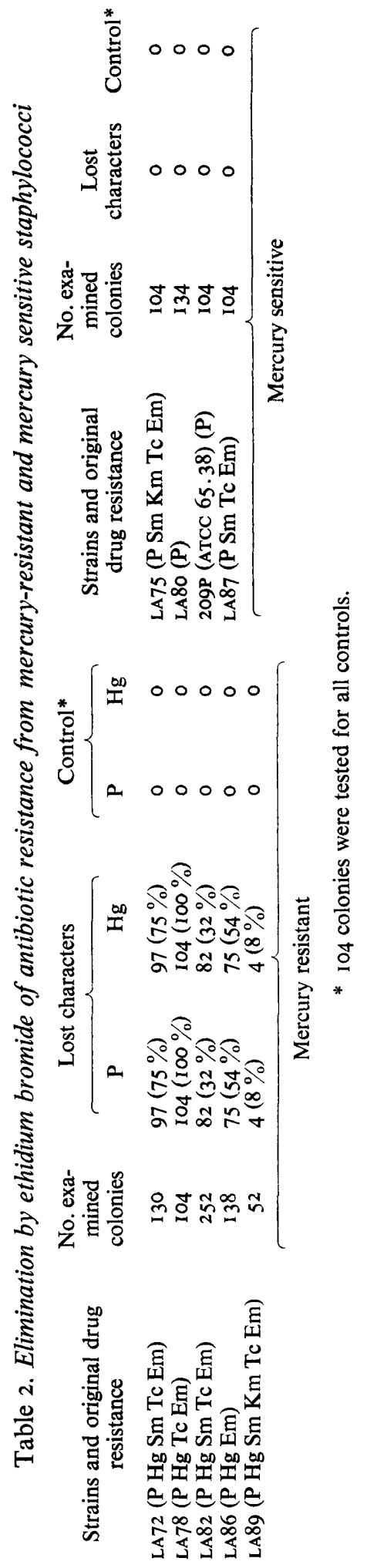


served. These strains were multiresistant or resistant to benzylpenicillin only, but all mercury sensitive.

Relations between inhibitory activity and resistance elimination by ethidium bromide. As observed with acridine and other basic dyes, staphylococci were more sensitive to ethidium bromide than were the enterobacteria examined. All strains of Staphylococcus aureus were inhibited at low concentrations $\left(8\right.$ to $\left.\mathrm{I}_{2} \times \mathrm{IO}^{-6} \mathrm{M}\right)$, but very important differences in minimal inhibitory concentrations were observed with the enterobacteria: $75 \times 10^{-6} \mathrm{M}$ for Shigella flexneri LA56. R22, and $3125 \times 10^{-6} \mathrm{M}$ for Salmonella derby LA46.R33. Subinhibitory concentrations with maximal eliminating effects are given in Table $\mathrm{I}$. The relation between ethidium bromide concentration, inhibition of growth and elimination of resistance in $S$, aureus LA78 and Sh. flexneri LA56. R22 are shown in Fig. $I$.

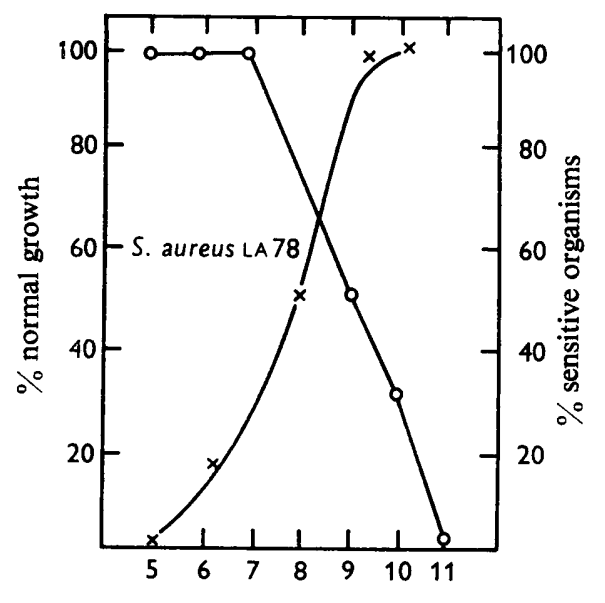

Ethidium bromide $\left(\times 10^{-6} \mathrm{M}\right)$

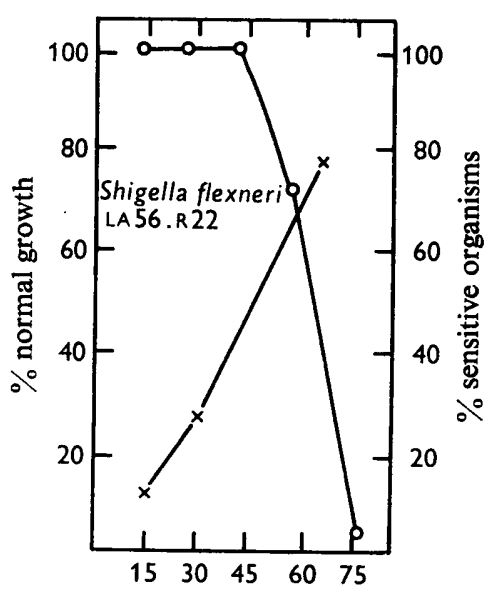

Ethidium bromide $\left(\times 10^{-6} \mathrm{M}\right)$

Fig. I. Relations between ethidium bromide concentration, inhibition of growth and percentage of antibiotic sensitive colonies in Staphylococcus aureus LA78 and Shigella flexneri LA56.R22. $0---O$, Percentage of normal growth in overnight culture (turbidimetric reading at $620 \mathrm{~m} \mu) ; \times---\times$, percentage of sensitive organisms.

Effects of light, manganese concentration and $p H$ value on growth and elimination of resistance. The inhibitory activity of ethidium bromide on growth was significantly increased when organisms were incubated in serial concentrations of ethidium bromide in the presence of light ( $40 \mathrm{~cm}$. from a white lamp of $100 \mathrm{~W})$; the growth of Staphylococcus aureus $\mathrm{LA} 78$ was inhibited at $7 \times 10^{-6} \mathrm{M}\left(\mathrm{I} \times \mathrm{IO}^{-6} \mathrm{M}\right.$ in absence of light). At subinhibitory concentration of ethidium bromide in the presence of light, 50 to $100 \%$ of the bacteria lost antibiotic resistance. Although it has been shown that $0.33 \mathrm{~mm}$-manganese sulphate antagonized ethidium bromide induced growth inhibition (Tomchick \& Mandel, 1964), no effect of manganese was observed on the elimination of antibiotic resistance in Shigella flexneri LA56. R22. Effects of different $\mathrm{pH}$ values on growth and elimination of resistance are shown in Table 3.

Absence of ethidium bromide selective effect. The possibility of selection by ethidium bromide of spontaneously sensitive bacteria was studied in Shigella flexneri LA56. Growth of an originally resistant strain carrying factor $\mathbf{R 2 2}$ and of a 'cured' sensitive 
strain was inhibited at exactly the same concentration of ethidium bromide $\left(75 \times 10^{-6} \mathrm{M}\right)$. There was no significant difference in growth rates of these strains with $60 \times 10^{-6} \mathrm{M}$ ethidium bromide, which eliminates factor R22 (Fig. I). Identical results were obtained by Watanabe \& Fukasawa (196I) with acridine dyes and according to them, a selective effect of ethidium bromide can be excluded.

Table 3. Effects of variations of pH value on elimination by ethidium bromide of resistance to penicillin and mercury from Staphylococcus aureus LA78

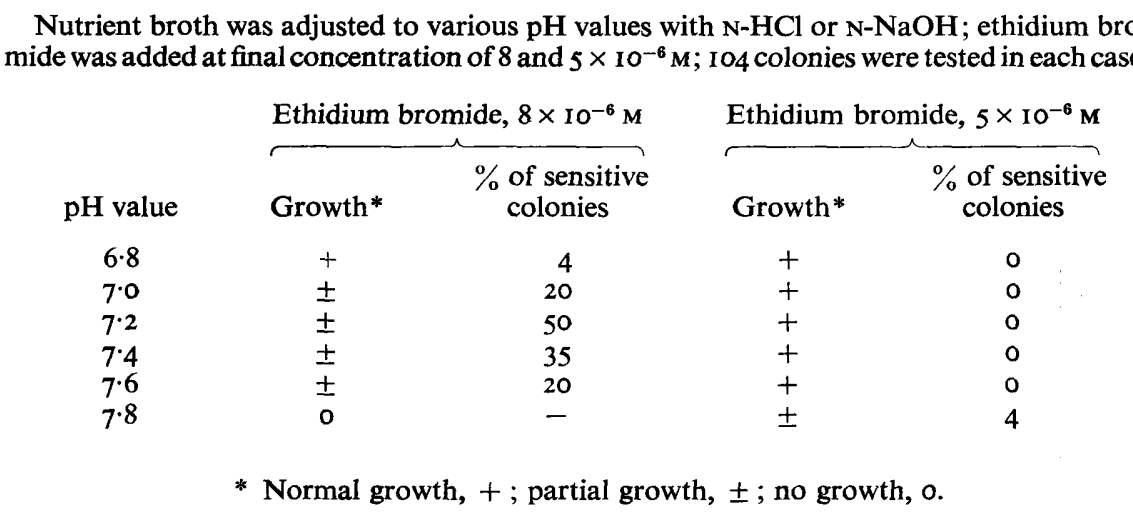

\section{DISCUSSION}

It is reported here that ethidium bromide eliminates some antibiotic resistance determinants and the $\mathrm{F}^{\prime}$-lac ${ }^{+}$factor. Elimination of $\mathrm{R}$ factors by acridine dyes in Enterobacteriaceae has been reported by Mitsuhashi, Harada \& Kameda (I96I), and Watanabe \& Fukasawa (196I); the frequencies of elimination were generally low, particularly in Escherichia coli. In our experiments, factors R4 and R22 were eliminated by ethidium bromide at high frequencies, from originally resistant strains and from two strains of $E$. coli $\mathrm{KI} 2$ to which factor $\mathrm{R} 22$ had been transferred. The bacteria became sensitive to all the drugs tested, and in contrast to the results of Mitsuhashi et al. (I96I), no difference was observed in elimination of factor R22 in Shigella flexneri and E. coli KI 2. With Salmonella derby LA7I, only one isolated resistance character was eliminated at a very high frequency (100\%). In this strain, only this suppressible character was transferred to sensitive bacteria. Conversely, no elimination of resistance characters was observed with $E$. coli LA49.RI 5 and $S$. paratyphi B LA43.R8 carrying R factors transferable to sensitive $E$. coli KI2. Factor RI5 was successively transferred to $E$. coli $\mathrm{KI} 2 \mathrm{c} 600 \mathrm{~F}^{-}-\mathrm{lac}^{-}$and to $E$. coli $\mathrm{KI} 254 \mathrm{I} 17 \mathrm{~F}^{-}-\mathrm{lac}^{+} ; 90$ to $100 \%$ of sensitive recipient cells became resistant in each case. Although factor RI5, transferred at very high frequency was apparently extra-chromosomal and de-repressed (Meynell \& Datta, I967), ethidium bromide did not eliminate factor $\mathrm{R}_{15}$ from originally resistant E. coli LA49. RI5, or from E. coli $\mathrm{K}_{12} 54 \mathrm{II}_{7}$ and c600 carrying RI5. The influence of recipient strains can be excluded in this system, because factor R22 (showing the same resistance pattern as $\mathrm{R}_{15}$ ) was eliminated at high frequency from originally resistant Sh. flexneri and E. coli KI2 54II7.R22 and C600.R22. 
It has been previously shown that with some strains of Staphylococcus aureus, penicillin resistance and erythromycin resistance were eliminated by acridine dyes, separately or jointly, at generally low frequencies: 0.1 to $3.5 \%$ (Hashimoto, Kono \& Mitsuhashi, 1964), 0.2 to $0.5 \%$ (Harmon \& Baldwin, 1964) and 0.6 to $3.9 \%$ (Baudens, Gerbaud \& Chabbert, 1965) for penicillin resistance; 2 to $8 \%$ (Mitsuhashi, Morimura, Kono \& Oshima, 1963) for erythromycin and other macrolides resistance; 0.1 to $3.5 \%$ (Mitsuhashi, Hashimoto, Kono \& Morimura, 1965) for joint elimination of penicillin and erythromycin resistances. Novick (1963) reported that no elimination of antibiotic resistance by acriflavine was observed with his strains.

Penicillin resistance was eliminated by ethidium bromide in five multiresistant strains of Staphylococcus aureus, at higher frequencies (8 to 100 \%); 'curing' concentrations of ethidium bromide $\left(5\right.$ to $\left.10 \times \mathrm{IO}^{-6} \mathrm{M}\right)$ were lower than acriflavine concentrations reported by different workers ( 50 to $100 \times \mathrm{IO}^{-6} \mathrm{M}$ ). Elimination of penicillin resistance was observed at a concentration which did not inhibit penicillinase synthesis. This finding agrees with previous results showing that protein formation was relatively unaffected by ethidium bromide (Tomchick \& Mandel, 1964). Also, in our experience, penicillin sensitivity remained stable in absence of ethidium bromide.

The five strains of Staphylococcus aureus in which penicillin resistance was eliminated were mercury resistant, and mercury resistance was always co-eliminated with penicillin resistance. It has been reported that these two markers were co-transduced and co-eliminated spontaneously or by acriflavine (Richmond \& John, 1964; Asheshov, 1966). In four strains of $S$. aureus, penicillin resistance was not eliminated. These strains were resistant to penicillin or to several antibiotics, but were sensitive to mercury salts. Chromosomal location for penicillin resistance determinants, not eliminated by acriflavine or high temperature, has been suggested (Asheshov, 1966).

Although it has been reported by Miller \& Harmon (1967) that genetical determinants controlling penicillin and mercury resistance in one strain of Staphylococcus aureus were co-transduced with chromosomal determinant responsible for methionine synthesis, it seems that in our strains, mercury resistance is generally associated with 'curable' and probably extra-chromosomal penicillin resistance determinants.

In strains of Staphylococcus aureus where penicillin and mercury resistances were eliminated at high frequencies ( 8 to $100 \%$ ), no elimination of erythromycin resistance was observed. There is no close linkage of penicillin and erythromycin resistance determinants in these strains, which seem to offer a different system from those previously described by Novick (1967).

The partially selective effect of acriflavine and ethidium bromide on extra-chromosomal DNA synthesis remains unclear. It was reported (Lepecq \& Paoletti, 1967) that there was no difference in ethidium bromide fixation on DNA of different origin, but that the linear or circular form of DNA affects drug fixation (Hudson \& Vinograd, 1967). Although there are some differences in drug penetration in different strains of Enterobacteriaceae, resistant organisms grown on high concentrations of ethidium bromide contained large amounts of drug, and it can be suggested that differences in DNA polymerase and RNA polymerase sensitivities are responsible for differences in ethidium bromide sensitivity of bacterial strains.

The present work has shown that ethidium bromide is a powerful drug in eliminating 
some resistance factors at high frequency with excellent reproducibility, and would appear to be a useful tool for further study of the lack of elimination of other resistance factors.

The authors thank Mr G. R. Gerbaud for excellent technical assistance.

\section{REFERENCES}

Asheshov, E. H. (1966). Chromosomal location of the genetic elements controlling penicillinase production in a strain of Staphylococcus aureus. Nature, Lond. 210, 804.

Baudens, J. G. \& ChabBert, Y. A. (1967). Analyse des facteurs de résistance transférables isolés en France. Annls Inst. Pasteur Paris 112, 565.

Baudens, J. G., Gerbaud, G. R. \& Chabbert, Y. A. (1965). Conséquences de la disparition sous l'influence de l'acriflavine de la production de pénicillinase chez les souches résistantes hétérogènes à la méthicilline, oxacilline et céphalothine. Annls Inst. Pasteur, Paris 109, 372.

Chabbert, Y. A. \& Baudens, J. G. (I966). Transmissible resistance to six groups of antibiotics in Salmonella infections. Antimicrobial Agents and Chemotherapy-1965. Ann Arbor: Amer. Soc. for Microbiol. p. 380.

Chabbert, Y. A., Baudens, J. G. \& Gerbaud, G. R. (1964). Variations sous l'influence de l'acriflavine, et transduction de la résistance à la kanamycine et au chloramphénicol chez les staphylocoques. Annls Inst. Pasteur, Paris 107, 678.

HARmon, S. A. \& Baldwin, J. N. (1964). Nature of the determinant controlling penicillinase production in S. aureus. J. Bact. 87, 593.

HASHIMOTO, H., KoNo, M. \& MrTSUHASHI, S. (1964). Elimination of penicillin resistance of Staphylococcus aureus by treatment with acriflavine. J. Bact. 88, 261 .

Hirota, Y. \& IuJma, T. (1957). Acriflavine as an effective agent for eliminating F factor in E. coli K 1 2. Nature, Lond. 180, 655.

Hudson, B. \& VINOGRAD, J. (1967). Catenated circular DNA molecules in HeLa cell mitochondria. Nature, Lond. 216, 647.

IKEDA, Y., IIIMA, T. \& TAJMA, K. (1967). Elimination of F-episome from a male strain of Escherichia coli by treatment with sarkomycin and a related antibiotic. J. gen. appl. Microbiol., Tokyo 13, 247.

LePeCQ, J. B. \& PaOletti, G. (1967). A fluorescent complex between ethidium bromide and nucleic acids. J. molec. Biol. 27, 106.

MeYnell, E. \& Datta, N. (1967). Mutant drug resistant factors of high transmissibility. Nature, Lond. 214, 885.

Miller, M. A. \& HARMon, S. A. (1967). Genetic associations of determinants controlling resistance to mercuric chloride, production of penicillinase and synthesis of methionine in $S$. aureus. Nature, Lond. 215, 531 .

MrtsuHAshi, S. (1965). Transmissible drug resistance factor R. Gunma J. Med. Sci. 14, I69.

MrTSUHASHI, S. (1967). Epidemiological and genetical study of drug resistance in Staphylococcus aureus. Jap. J. Microbiol. II, 49.

Mitsuhashi, S., Harada, K. \& Kameda, M. (196I). On the drug resistance of enteric bacteria (6): spontaneous and artificial elimination of transmissible drug resistance factors. Jap. J. exp. Med. 3I, I19.

Mitsuhashi, S., Hashimoto, H., Kono, M., Morimura, M. (1965). Joint elimination and joint transduction of the determinants of penicillinase production and resistance to macrolide antibiotics. J. Bact. 89, 988.

Mitsuhashi, S., Morimura, M., Kono, K. \& Oshima, H. (1963). Elimination of drug resistance of Staphylococcus aureus by treatment with acriflavine. J. Bact. 86, 162.

Novick, R. P. (1963). Analysis by transduction of mutation affecting penicillinase formation in Staphylococcus aureus. J. gen. Microbiol. 33, $12 \mathrm{I}$.

Novick, R. P. (1967). Penicillinase plasmids of Staphylococcus aureus. Fedn Proc. Fedn Am. Socs exp. Biol. 26, 29.

Novick, R. P. \& Richmond, M. H. (1965). Nature and interactions of the genetic elements governing penicillinase synthesis in Staphylococcus aureus. J. Bact. 90, 467. 
Perret, C. J. (1954). Iodometric essay of penicillinase. Nature, Lond. 174, 1012.

RichmoND, M. H. \& JoHN, M. (1964). Co-transduction by a staphylococcal phage of the genes responsible for penicillinase synthesis and resistance to mercury salts. Nature, Lond. 202, 1360.

STEERS, R. (1959). An inocular replicating apparatus for routine testing of bacteria susceptibility to antibiotics. Antibiotics Chemother. 9, 307.

ToMCHICK, R. \& MANDEL, H. G. (1964). Biochemical effects of ethidium bromide in micro-organisms. J. gen. Microbiol. 36, 225.

WARING, H. J. (1966). Cross-linking and intercalation in nucleic acids. Symp. Soc. gen. Microbiol. 16, 235.

WATANABE, T. (1967). Evolutionary relationships of $\mathrm{R}$ factors with other episomes and plasmids. Fedn Proc. Fedn Am. Socs exp. Biol. 26, 23.

WATANABE, T. \& FuKASAWA, T. (196I). Elimination of resistance factors by acridine dyes. J. Bact. 8I, 679. 